\title{
Dedication to Gennadi Henkin
}

\section{Steven G. Krantz ${ }^{1}$}

Published online: 16 January 2020

(c) Mathematica Josephina, Inc. 2020

Gennadi Henkin was a mentor to us all. An outstanding mathematical analyst, he had a profound influence over many parts of the subject. Ranging from function theory to complex analysis to the Cauchy-Riemann equations to Twistor theory to inverse problems and beyond, Henkin's interest and influence were far-reaching.

Henkin was a gentle and friendly soul, and welcomed many of us into the subject. My thesis was based on Henkin's work, and he had a notable influence on my entire mathematical life.

Gennadi Henkin was a friend to all who knew him. He was a founding editor of the Journal of Geometric Analysis and worked hard to establish this journal as a pre-eminent presence in modern mathematical publishing. He was respected and admired, and he will certainly be missed.

Publisher's Note Springer Nature remains neutral with regard to jurisdictional claims in published maps and institutional affiliations.

Steven G. Krantz

sk@math.wustl.edu

1 Washington University in St. Louis, One Brookings Drive, Campus Box 1146, St. Louis, MO 63130, USA 